\title{
UCLA
}

\section{Geotechnical Engineering}

\section{Title}

Laboratory investigation of the pre- and post-cyclic volume change properties of Sherman Island peat

Permalink

https://escholarship.org/uc/item/2k54r08t

\section{Journal}

Geocongress 2013 -- Stability and Performance of Slopes and Embankments III, 231(1)

\section{Authors}

Shafiee, Ali

Brandenberg, Scott J

Stewart, Jonathan $\mathrm{P}$

\section{Publication Date}

2013-03-06

Peer reviewed 


\title{
Laboratory Investigation of the Pre- and Post-Cyclic Volume Change Properties of Sherman Island Peat
}

\author{
Ali Shafiee ${ }^{1}$, Scott J. Brandenberg ${ }^{1}$, M ASCE, and Jonathan P. Stewart ${ }^{1}$, F ASCE \\ Dept. of Civil \& Environmental Engineering, University of California, Los Angeles, 5731 Boelter \\ Hall, Los Angeles, CA 90095, ashafiee@ucla.edu, jstewart@seas.ucla.edu, sjbrandenberg@ucla.edu
}

\begin{abstract}
We investigate through laboratory testing the volume change characteristics of peaty organic soil from Sherman Island, California under static conditions (consolidation, secondary compression) and post-cyclic conditions. Incremental consolidation tests indicate the material to be highly compressible $\left(C_{c}=\right.$ 3.9, $\left.C_{r}=0.4\right)$ and prone to substantial ageing from secondary compression $\left(C_{\alpha} / C_{c}=\right.$ 0.05 following virgin compression). Strain-controlled cyclic triaxial testing of the peat finds the generation of cyclic pore pressures for cyclic shear strain levels beyond approximately $0.5-1.0 \%$, with the largest residual pore pressure ratios $r_{u r}$ (cyclic residual pore pressure normalized by pre-cyclic consolidation stress) being approximately 0.2-0.4. Post cyclic volume change occurs from pore pressure dissipation and secondary compression. The level of post-cyclic secondary compression increases with $r_{u r}$. Many of these phenomena have not been documented previously and suggest the potential for seismic freeboard loss in levees due to mechanisms other than shear failure.
\end{abstract}

\section{INTRODUCTION}

The Sacramento-San Joaquin Delta consists of more than 60 islands that are mostly below sea level, and protected by more than $1700 \mathrm{~km}$ of levees that constantly impound water. Delta levees are composed of poorly compacted sands, silts, clays and peat that are often constructed atop a thick layer of peaty organic soil. The stability of these levees is of great importance, since inundation of any of the major islands can draw saline water from the San Francisco Bay into the Delta, halting water exports to the central valley and southern California. Several potential failure mechanisms can occur for levees founded on peat that experience strong ground motion, including settlement due to volumetric and/or deviatoric straining in foundation soils brought on by cyclic pore pressure generation and associated 
reconsolidation and softening. In this article, we present preliminary results of a laboratory investigation of volume change characteristics in peat, which is designed in part to investigate the feasibility of this potential levee failure mechanism along with providing insights into the fundamental behavior of this important soil type.

The dynamic properties of peat that have been most substantially investigated in prior work are the variations of shear modulus and damping ratio with cyclic shear strain. As described by Wehling et al. (2003), tests performed on peats from Mercer Slough in Washington (Kramer, 2000), Queensboro bridge in New York (Stokoe et al., 1996), and Sherman Island in California (Boulanger et al., 1998; Wehling et al., 2003) show a wide range of behavior from relatively linear (i.e., modest modulus reduction, modest damping) at high effective consolidation stresses (over $40 \mathrm{kPa}$ ) to strongly nonlinear at low stresses (generally 10-40 kPa). Testing performed on relatively undisturbed tube samples along with pre-sheared and re-consolidated specimens indicated that the effect of sample disturbance on the modulus reduction and damping relations was small (Wehling et al., 2003). A statistical model for the dynamic properties of organic soils was proposed by Kishida et al. (2009). Shear modulus and damping were formulated as functions of cyclic shear strain amplitude, consolidation stress, organic content, and ratio of laboratory-to-field consolidation stresses. These prior studies of dynamic properties did not investigate post-cyclic volume change.

Volume change characteristics of peaty organic soil have been investigated by Dhowian and Edil (1980), Fox and Edil (1992), Mesri et al., (1997), and Mesri and Ajlouni (2007), among others. These studies mostly focus on measurement of consolidation parameters (e.g., virgin compression index, coefficient of consolidation) and secondary compression parameters. Factors controlling the compressibility characteristics of peat include the fiber content, void ratio, initial permeability, nature and arrangement of particles, and inter-particle chemical bonding (Mesri and Ajlouni, 2007). Fibrous peats are highly compressible, with virgin compression indices $\left(C_{c}\right) 5$ to 20 times those of soft clay (Mesri and Ajlouni, 2007). Fox and Edil (1992) showed that the secondary compression index $c_{\alpha}$ is not constant but increases with time. Mesri et al. (1997) suggest a range of 0.05 to 0.07 for $C_{d} / C_{c}$.

We are not aware of prior studies investigating volume change characteristics of peats associated with cyclic loading. In this study, we investigate static and postcyclic volume change characteristics of samples of peaty organic soil obtained from a free-field site on Sherman Island, California. Measurements include consolidation tests and strain-controlled cyclic triaxial tests with post-cyclic volume change measurements. The results of this study will be used in subsequent work to develop simple relations for estimating post-earthquake settlement of levees caused by reconsolidation of peat, and to calibrate an advanced constitutive model for use in numerical simulations.

\section{SITE CHARACTERISTICS AND SAMPLING TECHNIQUE}

Nine boreholes were drilled, and 24 undisturbed samples were taken from a freefield site on Sherman Island at different depths ranging from approximately 1 to $6 \mathrm{~m}$. This site is also being used for cyclic testing of a model levee embankment section 
(Reinert et al., 2012). Soil samples were obtained with a piston sampler designed to be deployed in a hand auger borehole. We found that the unsupported borehole would squeeze shut at a depth of typically 2 to $3 \mathrm{~m}$, so the piston sampler was lowered to the bottom of the borehole and subsequently advanced by hand to the desired depth with the piston locked at the bottom of the tube (i.e., the tube was simply pushed into the ground to depths of $6 \mathrm{~m}$ by hand). This procedure can only be utilized in extremely soft soils. When the sampler had been advanced to the desired depth, the piston was unlocked and the tube was pushed into the peat. Water was poured on top of the piston to generate suction to help retain the sample, and the sampler was subsequently retracted. We obtained full recovery for every sample using this method.

Figure 1 illustrates the geotechnical conditions at the test site. The cone penetration data was measured as part of this study, whereas the shear wave velocity $\left(V_{s}\right)$ profile is from suspension logging approximately $2 \mathrm{~km}$ from the test site at a location with similar geotechnical conditions (GeoVision 2000). The top $11 \mathrm{~m}$ of the site consists of Holocene peaty organic soils, which are underlain by Pleistocene dune sands to the maximum depth of $20 \mathrm{~m}$ explored in the site investigation. Formation of the peaty organic soil stratum began about 11,000 years ago from decomposition of plant materials (CDWR 1992). As shown in Fig. 1, the peat layer has very low (near zero) CPT tip resistance $\left(q_{c}\right)$ and a mean $V_{s}$ of approximately $25 \mathrm{~m} / \mathrm{s}$. A simple surface wave travel time measurement at the site confirmed that the average Rayleigh wave velocity in the peat was about $26 \mathrm{~m} / \mathrm{s}$.
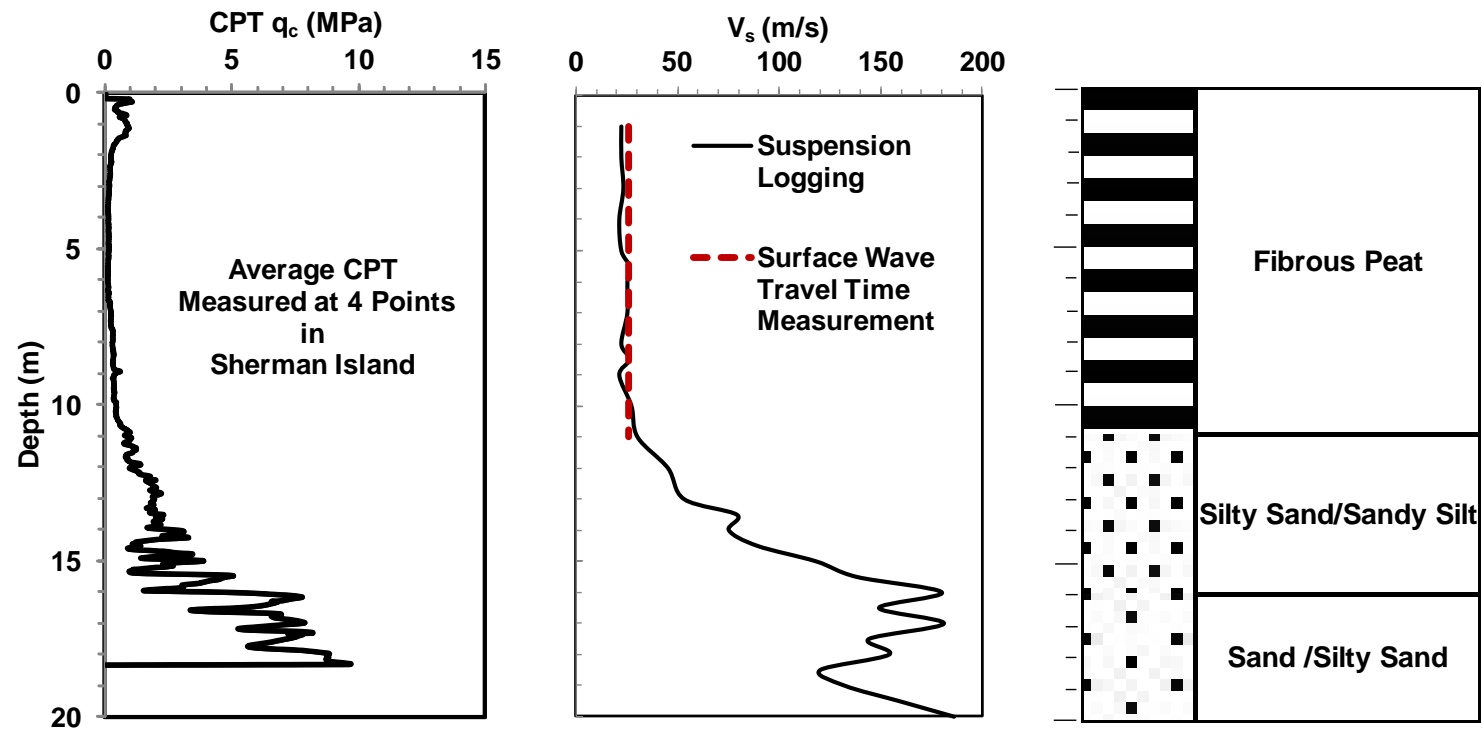

FIG. 1. CPT tip resistance $\left(q_{c}\right)$, and shear wave velocity $\left(V_{s}\right)$ from a free-field site on Sherman Island ( $V_{s}$ profile from GeoVision 2000)

\section{TESTED MATERIAL AND PROCEDURE}

The samples used for testing of various types are summarized in Table 1. In this article, we focus on testing performed on samples from a depth range of 2.5-3.0 m, 
which is below the seasonally fluctuating water table. Index tests indicate water contents ranging from $410 \%$ to $480 \%$ and specific gravity of 1.85 . Hydraulic conductivity was measured in the traxial device following ASTM D5084 (ASTM, 2010a). The diameter and height of the tested specimen were $5 \mathrm{~cm}$, and the hydraulic gradient was varied from 10 to 30, while consolidation pressure increased from 8 to $48 \mathrm{kPa}$. Consolidation tests were performed per ASTM D2435 (ASTM, 2010b) using incremental loading and variable consolidation time as described further in Section 4.1.

Cyclic triaxial tests were performed in several stages. In the first stage, the peaty organic soils were isotropically consolidated to the stresses indicated in Table 1, which are either the in situ free-field effective stresses at the sample depths $\left(\sigma_{v c}^{\prime}\right)$ or the estimated consolidation stress beneath the crest of Sherman Island levees. This consolidation occurred over a relatively short time interval that is intended to complete normal consolidation and minimize pseudo-overconsolidation from secondary compression, as described further below. Following consolidation, straincontrolled multi-stage cyclic shearing was performed in stages having axial strain amplitudes ranging from $1.3 \times 10^{-3}$ to $2.4 \%$ (equivalent shear strains of $1.9 \times 10^{-3}$ to $3.6 \%$ ). Each stage of loading consisted of 15 uniform strain cycles at a loading frequency of $0.1 \mathrm{~Hz}$. Following each stage of cyclic shearing, drainage valves were opened, and post-cyclic deformations and volume changes were monitored for variable time intervals, as indicated in Table 1. Strain-controlled tests were preferred instead of stress controlled tests because prior work on other soil types has shown shear strain to be a more fundamental parameter controlling pore pressure generation and volume change (e.g., Vucetic, 1994).

Table 1. Testing plan for undisturbed samples taken from a depth of $2.5-3.0 \mathrm{~m}$

\begin{tabular}{|c|c|c|c|}
\hline Specimen & Borehole & Test & $\sigma_{v c}^{\prime}(\mathbf{k P a})$ \\
\hline 8-3a & 8 & Hydraulic Conductivity & 8 to 48 \\
\hline 8-3b & 8 & 1 D-Consolidation & 13 to 195 \\
\hline 8-3c & 8 & Cyclic, followed by brief consolidation (20 min) & 8 \\
\hline 8-3d & 8 & Cyclic, followed by brief consolidation & 40 \\
\hline 9-3a & 9 & Cyclic, followed by extended consolidation (24 hrs) & 9 \\
\hline 9-3a & 9 & Cyclic, followed by extended consolidation & 18 \\
\hline 9-3a & 9 & Cyclic, followed by brief consolidation & 42 \\
\hline
\end{tabular}

\section{TEST RESULTS}

\subsection{Hydraulic Conductivity and Consolidation}

Hydraulic conductivity $(k)$ was measured directly in the triaxial device as described in Section 3. Figure 2 shows the variation of $k$ with void ratio $(e)$, which follows the expected pattern of $k$ increasing with $e$. The slope of the relationship $C_{k}=d e / d \log k$ is approximately 2.4. This value of $C_{k}$ is approximately half of $e$, which is consistent with prior observations for clays (e.g., Fox, 1999). 
Figures 3 (a) and (b) show settlement vs time for a typical virgin compression increment from the consolidation tests using logarithmic and square root of time axes. The results in Figure 3(a) illustrate the difficulty in identifying the time of end of primary consolidation $\left(t_{c}\right)$, which stems from the similarity of the slopes in the primary consolidation and secondary compression phases of the test (also observed by Fox and Edil, 1992). Hence, consolidation was continued over a duration sufficient to define a representative curve using the square-root of time axis (Figure $3 b$ ), which was typically 24 hours. For use in this study, we approximate $t_{c}$

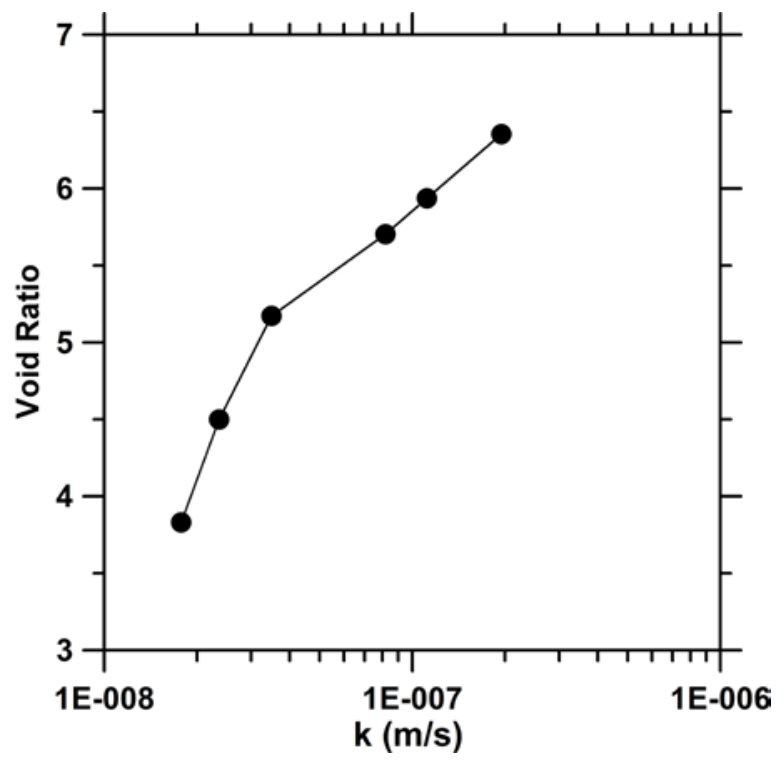

FIG. 2. Hydraulic conductivity of peat from falling head tests (specimen 8-3a) as the value of $t_{90}$ obtained from Taylor's procedure (e.g., Terzaghi et al., 1996). Using this definition of $t_{c}$, the fraction of the total volume change within each load increment associated with primary consolidation (for $t<t_{c}$ ) and secondary compression (for $t>t_{c}$ ) is identified.
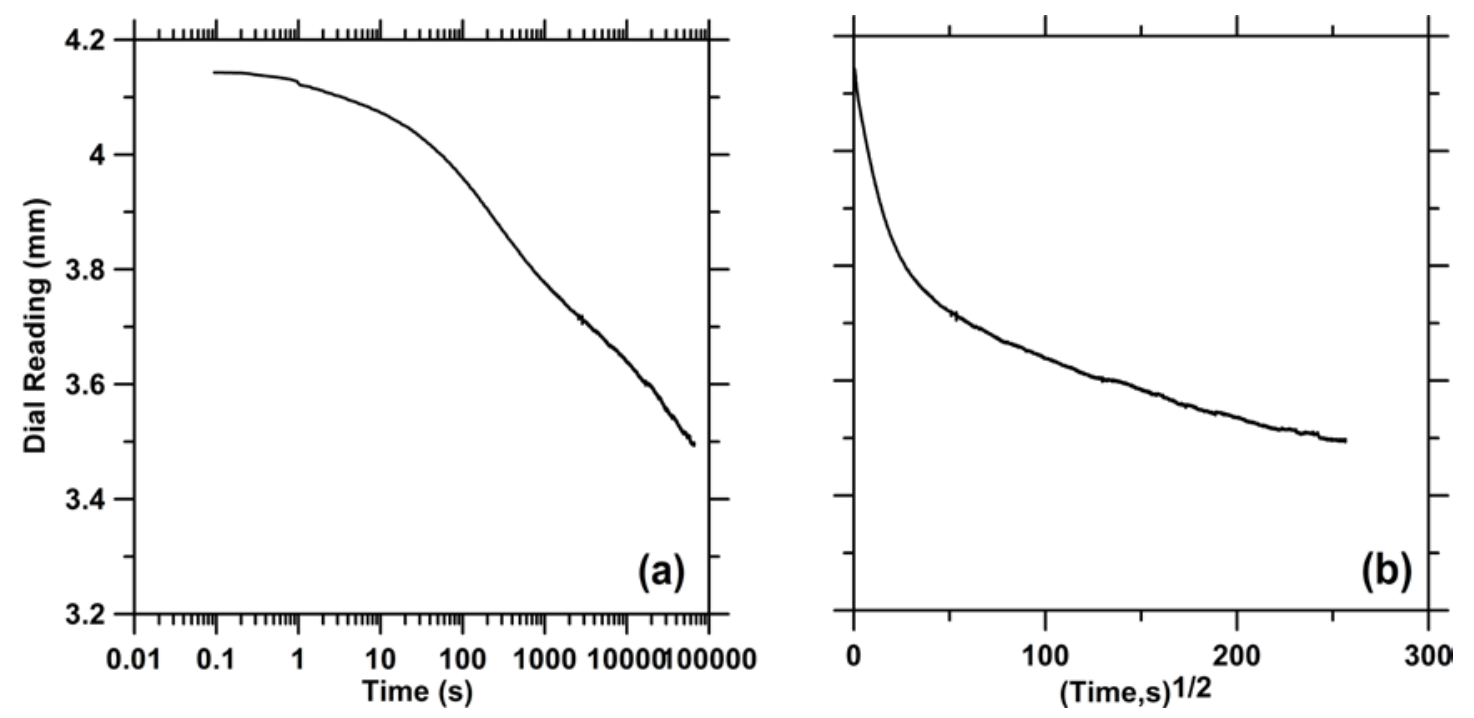

FIG. 3. Typical settlement-time plots for an increment of load applied to peat. Specimen 8-3b, final $\sigma_{v c}^{\prime}=195 \mathrm{kPa}$

A consolidation curve evaluated using this process is shown in Figure 4. The stepped line indicates the volume change in each load increment from secondary 
compression (vertical steps) and primary consolidation (pair of sloped lines for recompression and virgin compression). Void ratios at the end of load increments fall below the consolidation curve due to secondary compression. The virgin compression index is interpreted from the consolidation curve as $C_{c}=3.9$, whereas the recompression index is $C_{r}=0.4$.

Using the portion of the settlementtime plots following $t_{p}$, the slope is computed from the change of void ratio over one log cycle of time $\left(C_{\alpha}\right)$. The ratio $C_{\alpha} / C_{c}$ was found to range from 0.044 to 0.065 , following virgin

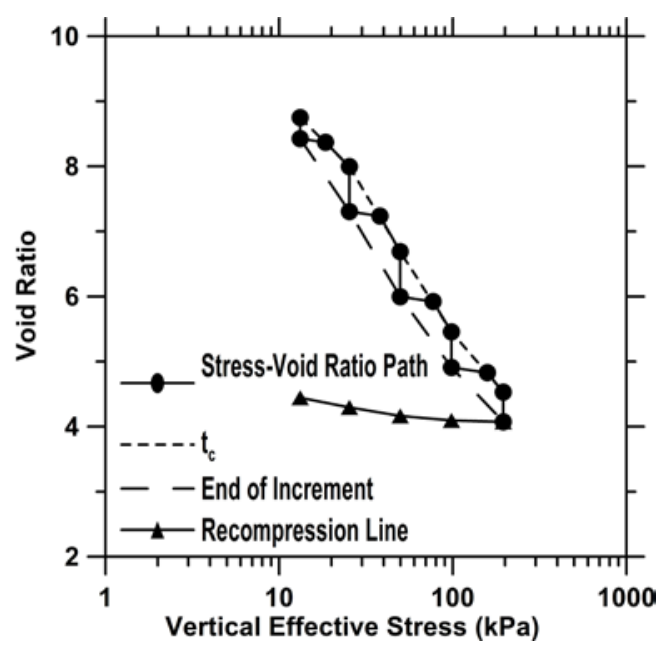

FIG. 4. Consolidation behavior of the tested peat (specimen 8-3b) compression increments, with an average of 0.05 . When the soil is overconsolidated (i.e., during unloading stages), $C_{\alpha} / C_{c}$ reduces to about 0.01 .

\subsection{Cyclic Triaxial Tests}

Undrained cyclic strain-controlled triaxial tests with post cyclic volume change measurements were conducted using the staged process described in Section 3. As shown in Table 1, we have performed five such test sequences on specimens from the 2.5-3.0 m depth range. Following undrained cyclic shear, specimens were consolidated over time intervals of 20 min (specimens 8-3c and 8-3d) and $24 \mathrm{hrs}$ (specimen 9-3a). Specimens with longer post-shear consolidation time experience a large fraction of their volume change from secondary compression; we seek to investigate the effect of prior cyclic loading on secondary compression behavior.

Figure 5 shows results of a typical test sequence, which was performed on specimen 9-3a $\left(\sigma_{v c}^{\prime}=42 \mathrm{kPa}\right)$. During cyclic loading, pore pressure ratio $r_{u}$ (i.e. excess pore pressure divided by consolidation stress) increases and the soil stiffness degrades as evidenced by reductions in the shear stress to achieve the uniform strain amplitude. Figure 6(a) shows for each increment of shearing the residual pore pressure at the end of cycle 15, which we denote $r_{u r}$, as a function of the shear strain amplitude $\left(\gamma_{c}\right)$. The pore pressure generation markedly increases for cyclic strain amplitudes larger than $0.5-1.0 \%$. The largest observed pore pressure ratios were in the range of 0.2-0.4, which is much lower than those for liquefiable sands or cyclic softened normally consolidated clays (e.g., Boulanger and Idriss, 2007).

As described in Section 3, following the end of cyclic loading, the drain valve was opened and post-cyclic volumetric strain was monitored as a function of time. Figure 6(b) shows the vertical strain after $1200 \mathrm{~s}$ (20 min), which nearly corresponds to the end of primary consolidation $\left(t_{c}\right)$. As with $r_{u r}$, there is an increasing trend of $\varepsilon_{v}$ with $\gamma_{c}$, which is expected because this volume change is associated with primary 
consolidation that dissipates the excess pore pressures. We verify this hypothesis by computing the theoretical volume change associated with recompression over the stress increment produced by pore pressure generation:

$$
\varepsilon_{v, P C}=\frac{-C_{r}}{1+e_{0}} \log \left(1-r_{u r}\right)
$$

where $e_{o}$ is the soil void ratio at the start of post-cyclic consolidation. The results of this calculation are shown in Figure 7, which shows an excellent match to the data, confirming that the volume change at $20 \mathrm{~min}$ of consolidation time is dominated by primary consolidation.
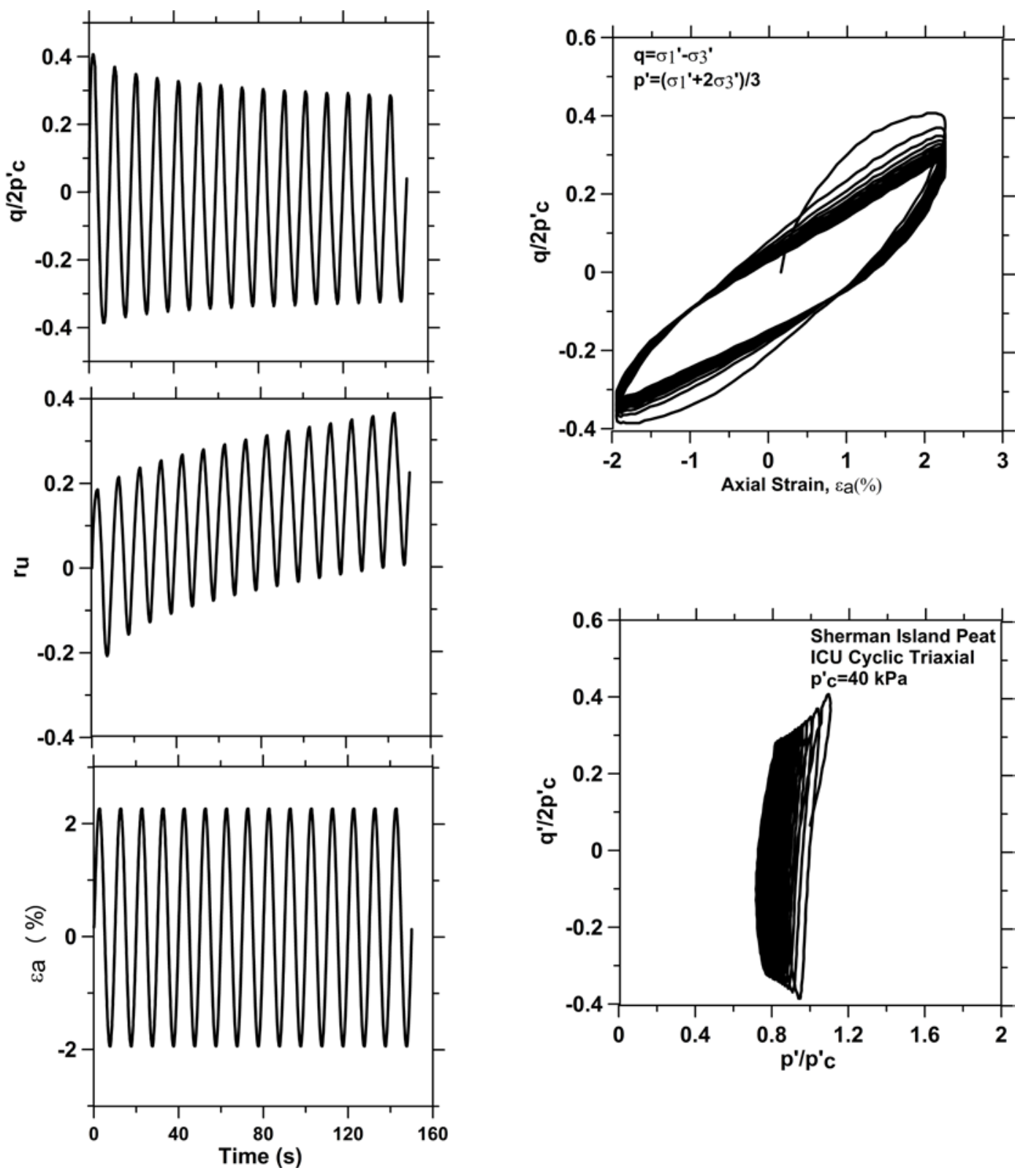

FIG. 5. Cyclic behavior of specimen 9-3a 

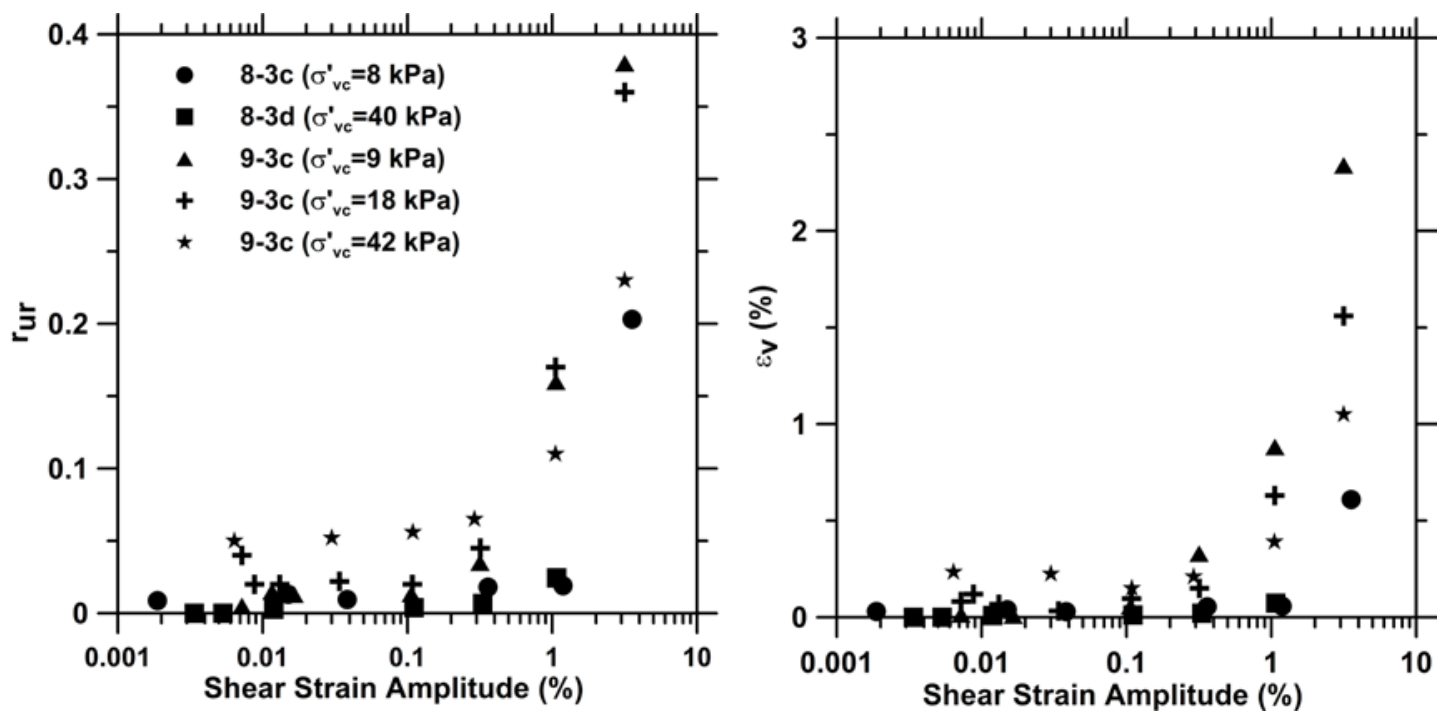

FIG. 6 Post-cyclic behavior of the tested peat (a) residual pore pressure, and (b) post-cyclic volume change at $20 \mathrm{~min}$

As noted previously, several specimens were allowed to reconsolidate after cyclic shearing beyond 20 min to 24 hours. For most of this additional time, the volume change is dominated by secondary compression. By looking at the varying levels of volume change from secondary compression for different shear strain amplitudes, we investigate the effects of prior cyclic shearing on post-cyclic secondary compression. This effect is shown graphically in Figure 7, where the volumetric strain after 24 hours is shown along with that at $20 \mathrm{~min}$. The difference between these two curves, which is from secondary compression, increases with shear strain amplitude, indicating that indeed cyclic shearing has an effect on post-cyclic secondary compression.

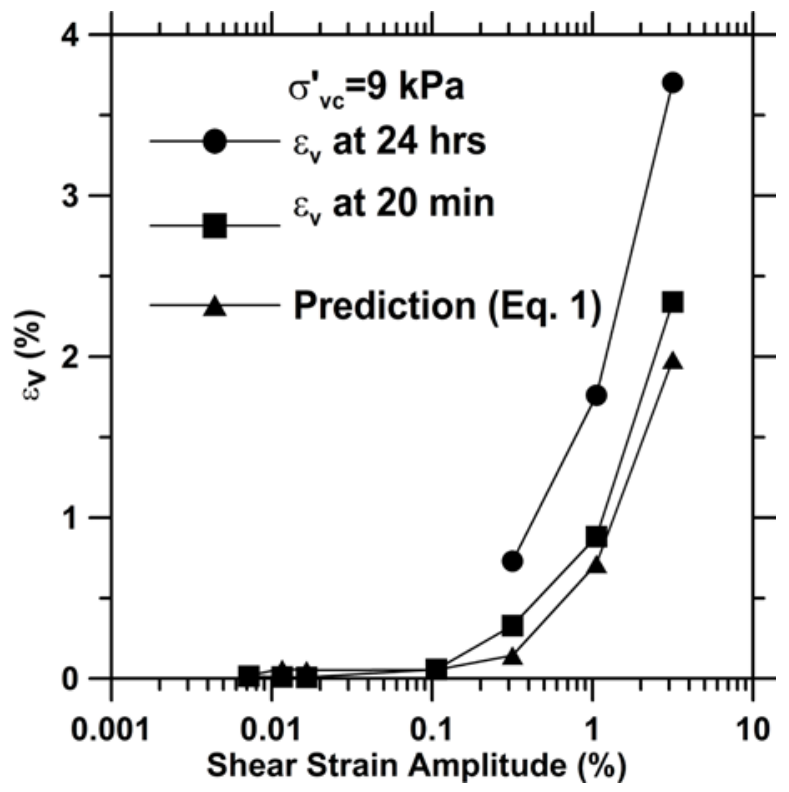

FIG. 7. Effect of cyclic loading on the secondary compression (specimen 9-3a) 
Further analysis of settlement-time curves (not shown here for brevity) during this time increment (20 min to $24 \mathrm{hrs}$ ) indicates that $C_{\alpha}$ changes with shear strain amplitude such that $C_{\alpha} / C_{c}$ increases from 0.01 to 0.02 when shear strain amplitude increases from $0.3 \%$ to $3 \%$. These levels of $C_{\alpha} / C_{c}$ are of the same order as those following re-compression in conventional consolidation tests.

\section{SUMMARY AND CONCLUSIONS}

We have performed incremental consolidation tests and sequences of undrained cyclic shearing tests on a triaxial apparatus to investigate volume change characteristics of peat from Sherman Island, California. As has been found in prior research on other peat materials, Sherman Island peat is highly compressible and quite pervious. Primary consolidation is substantial but occurs relatively quickly. Secondary compression is a substantial contributor to volume change, and ratios of secondary compression index to virgin compression index $\left(C_{d} / C_{c}\right)$ are in the range observed in prior work.

The cyclic testing indicates that the peat generates positive pore pressure ratios upon cyclic loading, although those ratios were observed to be relatively low as compared to liquefiable sands or clays undergoing cyclic softening. Accordingly, at the strain levels investigated, pore pressure induced strength loss in the peats is likely modest (but has not been formally investigated to date). On the other hand, for large cyclic shear strains above approximately $0.5-1.0 \%$, accumulated pore pressures result not only in significant volumetric strains from primary consolidation, but also from substantial secondary compression. Interestingly, the secondary compression index seems to have some dependence on strain amplitude, increasing as the level of cyclic strain amplitude increases.

\section{ACKNOWLEDGEMENTS}

Support for this research was provided by the U.S. Geological Survey (USGS), Department of the Interior, under USGS award number 11HQPAQ001. This support

is gratefully acknowledged. The views and conclusions contained in this document are those of the authors and should not be interpreted as necessarily representing the official policies, either expressed or implied, of the U.S. Government. This manuscript is based upon research performed in a collaboratory renovated with partial funding from the National Science Foundation under Grant No. 0963183, which is an award funded under the American Recovery and Reinvestment Act of 2009 (ARRA). We wish to thank the two anonymous reviewers for their helpful comments.

\section{REFERENCES}

ASTM. (2010a). "Standard test methods for measurement of hydraulic conductivity of saturated porous materials using a flexible wall permeameter.” D5084, West Conshohoken, Pa. 
ASTM. (2010b). "Standard test methods for one-dimensional consolidation properties of soils using incremental loading.” D2435 / D2435M , West Conshohoken, Pa.

Boulanger, R. W., Arulnathan, R., Harder, L. F., Jr., Torres, R. A. and Driller, M. W. (1998). "Dynamic properties of Sherman Island peat.” J. Geotech. Geoenviron. Eng., 124(1): 12-20.

Boulanger, R.W. and Idriss, I.M. (2007). "Evaluation of cyclic softening in silts and clays." J. Geotech. \& Geoenviron. Eng., 133(6): 641-652.

CDWR (1992). "Seismic stability evaluation of the Sacramento-San Joaquin Delta levees.” Phase I Report: Preliminary Evaluations and Review of Previous Studies, Division of Engineering, California Department of Water Resources (CDWR).

Dhowian, A.W. and Edil, T.B. (1980). Consolidation behavior of peats. Geotech. Testing J., 3(3): 105-114.

GeoVision (2000). "Department of water resources boreholes DHP-4D and DHP-5J3 suspension P\&S velocities” prepared for California Water Department Resources.

Fox, P.J. and Edil, T.B. (1992). " $C_{\alpha} / C_{c}$ Concept applied to compression of peat,” $J$. Geotech. Eng., 118(8): 1256-1263.

Fox, P.J. (1999). "Solution charts for finite strain consolidation of normally consolidated clays,” J. Geotech. \& Geoenviron. Eng., 125(10): 847-867.

Kishida, T., Boulanger, R.W., Abrahamson, N.A., Wehling, T.A. and Driller, M.W. (2009). "Regression models for dynamic properties of highly organic soils.” J. Geotech. \& Geoenv. Eng., 133(7): 851-866.

Kramer, S. L. (2000). “Dynamic response of Mercer Slough peat.” J. Geotech. \& Geoenv. Eng., 135(4), 533-543.

Mesri G. and Ajlouni, M. (2007). “Engineering properties of fibrous peats.” $J$. Geotech. \& Geoenv. Eng., 133(7): 851-866.

Mesri G., Stark T.D., Ajlouni, M.A., and Chen, C.S. (1997). "Secondary compression of peat with or without surcharge. "J. Geot. \& Geoenv. Engrg., 123(5): 411-421.

Reinert, E.T., Brandenberg, S.J., Stewart, J.P., and Moss, R.E.S. (2012). "Dynamic field test of a model levee founded on peaty organic soil using an eccentric mass shaker,” Proc. 15 th World Conf. on Eqk. Eng., Lisbon, Portugal. In press.

Stokoe, K. H., II, Bay, J. A., Rosenbald, B. L., Hwang, S. K. and Twede, M. R. (1996). " In situ seismic and dynamic laboratory measurements of geotechnical materials at Queensboro Bridge and Roosevelt Island.” Geotechnical Engineering Rep. No. GR94-5, Civil Engineering Dept., Univ. of Texas at Austin, TX.

Terzaghi, K., Peck, R.B. and Mesri, G. (1996). Soil Mechanics in Engineering Practice, $3^{\text {rd }}$ Ed., Wiley, New York, NY.

Vucetic, M., (1994). "Cyclic threshold shear strains in soils," J. Geotechnical Engineering, 120 (12), 2208-2228.

Wehling, T.M., Boulanger, R.W., Arulnathan, R., Harder, L.F. and Driller, M.W. (2003). "Nonlinear Dynamic Properties of a Fibrous Organic Soil.” J. Geotech. \& Geoenv. Eng., 129 (10): 929-939. 